\title{
The Interaction between Air Quality and Meteorological Factors in an Arid Environment of Makkah, Saudi Arabia
}

\author{
Turki M. Habeebullah, Said Munir, Abdel Hameed A. A. Awad, Essam A. Morsy, Abdulaziz R. Seroji, \\ and Atif M. F. Mohammed
}

\begin{abstract}
Air quality and meteorological factors are closely linked through atmospheric chemical reactions and dynamic processes. Limited studies areconducted to determine the interactions between meteorological factors and air pollutants in an arid environment. The present study aims to investigate the association of air pollutants $\left(\mathrm{PM}_{10}, \mathrm{O}_{3}, \mathrm{NO}_{2}\right.$, and $\left.\mathrm{SO}_{2}\right)$ with meteorological parameters (wind speed, wind direction, relative humidity, temperature and rainfall) in the Holy City of Makkah, Saudi Arabia. Wind speed was positively correlated with $\mathrm{O}_{3}(r=0.34)$ and $\mathrm{PM}_{10}(r=0.17)$ and negatively correlated with NOx (r=-0.38), CO $(r=-0.39)$, and $\mathrm{SO}_{2} \quad(r=-0.04)$. Temperature was positively correlated with most of the pollutant, except $\mathrm{NO}(r=-0.05)$ and $\mathrm{SO}_{2}(r=-0.07)$. The effect of rainfall was either negative or insignificant on most of the pollutants. The analysis is further elaborated by graphical presentations, such as polar plots, correlation plots and advanced scatter plots.
\end{abstract}

Index Terms-Airpollution, meteorological parameters, Makkah, $\mathrm{NO}_{2}, \mathrm{PM}_{10}, \mathrm{O}_{3}$.

\section{INTRODUCTION}

In Makkah the concentrations of traffic related gaseous air pollutants (e.g., nitrogen oxides (NOx), carbon monoxide $(\mathrm{CO})$, and sulphur dioxide $\left.\left(\mathrm{SO}_{2}\right)\right)$ are below the air quality standards set by World Health Organization (WHO) and PME [1], however the concentrations of particulate matter $(\mathrm{PM})$ and ozone $\left(\mathrm{O}_{3}\right)$ sometimes violate the air quality limits. High levels of particulate matter with aero-dynamic diameter of 10 micron or less $\left(\mathrm{PM}_{10}\right)$ in Makkah, especially during the Hajj period have been previously reported by several authors [2]-[6]. The reasons for the high $\mathrm{PM}_{10}$ concentrations are most probably high volume of traffic, construction work, re-suspension of particles, windblown dust and sand particles and geographical conditions (Arid Regions) [5]. Most of the area of Saudi Arabia is made of deserts, which leads to a high concentration of dust in the air as wind blows onto inhabited areas from the neighboring desert lands [7]. The government of Saudi Arabia is continuously working on improving the air quality in Makkah. Steps undertaken for the reduction of air

Manuscript received June 7, 2014; revised November 5, 2014. This work was supported by the Custodian of the Two Holy Mosques Institute for Hajj and Umrah Research, Umm Al Qura University, Makkah, KSA.

The authors are with the Custodian of the Two Holy Mosques Institute for Hajj and Umrah Research, Umm Al Qura University, Makkah, KSA (e-mail t_habeebullah@yahoo.com, abed196498@yahoo.com,_e_morsy1@yahoo.com, seroji@uqu.edu.sa, ateffathy2006@yahoo.com). pollutant concentrations include the development of electric train system, continuous water spray program in the Holy Mosque, which has shown positive effect on $\mathrm{PM}_{10}$ concentration (data not published yet), and reducing the number of vehicles in the Holy Sites (Mina, Muzdalifah and Arafat), especially during the Hajj period.

A decrease or increase in air pollution concentration is the result of an imbalance between air pollutants production rates and air pollutants removal rates [8]. Meteorological parameters (e.g., temperature, wind, relative humidity) play a vital role in pollutants formation, and influence the transport, dispersion and chemical reactions of air pollutants [8]-[10]. Substantial variations in meteorological conditions can exert a large impact on various air pollutants concentrations and often mask long term trends in air pollutant concentrations [10], [11]. Air pollutant concentrations exhibit typical diurnal, weekly and annual cycles due to changes in meteorological parameters and emission of pollutants from their sources [12], [13].

The effect of meteorological conditions on air pollutants level in arid condition is not well understood. In this paper the interaction between air pollutant levels and meteorological parameters is analysed in Makkah, where published materials on air quality related issue is limited. This study will help better understand the interaction between meteorological conditions and various air pollutants, which is required for developing effective air quality management plan in Makkah.

\section{Methodology}

Air quality data of several air pollutants and meteorological parameters for year 2012 were analysed. The data were collected at the Presidency of Meteorology and Environment (PME) monitoring station. The monitoring station is situated near by the Holy Mosque (Al-Haram) in Makkah (Fig. 1). This is a continuous monitoring station and measures the concentrations of several air pollutants, including $\mathrm{SO}_{2}, \mathrm{CO}, \mathrm{PM}_{10}, \mathrm{NOx}, \mathrm{NO}, \mathrm{NO}_{2}$, and $\mathrm{O}_{3}$, and meteorological variables (e.g., wind speed and temperature). The monitoring stations were previously described by Munir et al., [6]. Air pollutant concentrations are expressed in microgram per cubic meter $\left(\mu \mathrm{g} / \mathrm{m}^{3}\right)$, except CO which is expressed in milligram per cubic meter $\left(\mathrm{mg} / \mathrm{m}^{3}\right)$. Wind speed is expressed in meter per second $(\mathrm{m} / \mathrm{s})$, wind direction in degree from the north, temperature in degree Celsius $\left({ }^{\circ} \mathrm{C}\right)$, relative humidity in percentage $(\%)$ and rainfall in millimeter per hour $(\mathrm{mm} / \mathrm{hr})$.

Statistical data analysis was carried out in the statistical software R programming language [14], and its package openair [15] and loa [16]. 


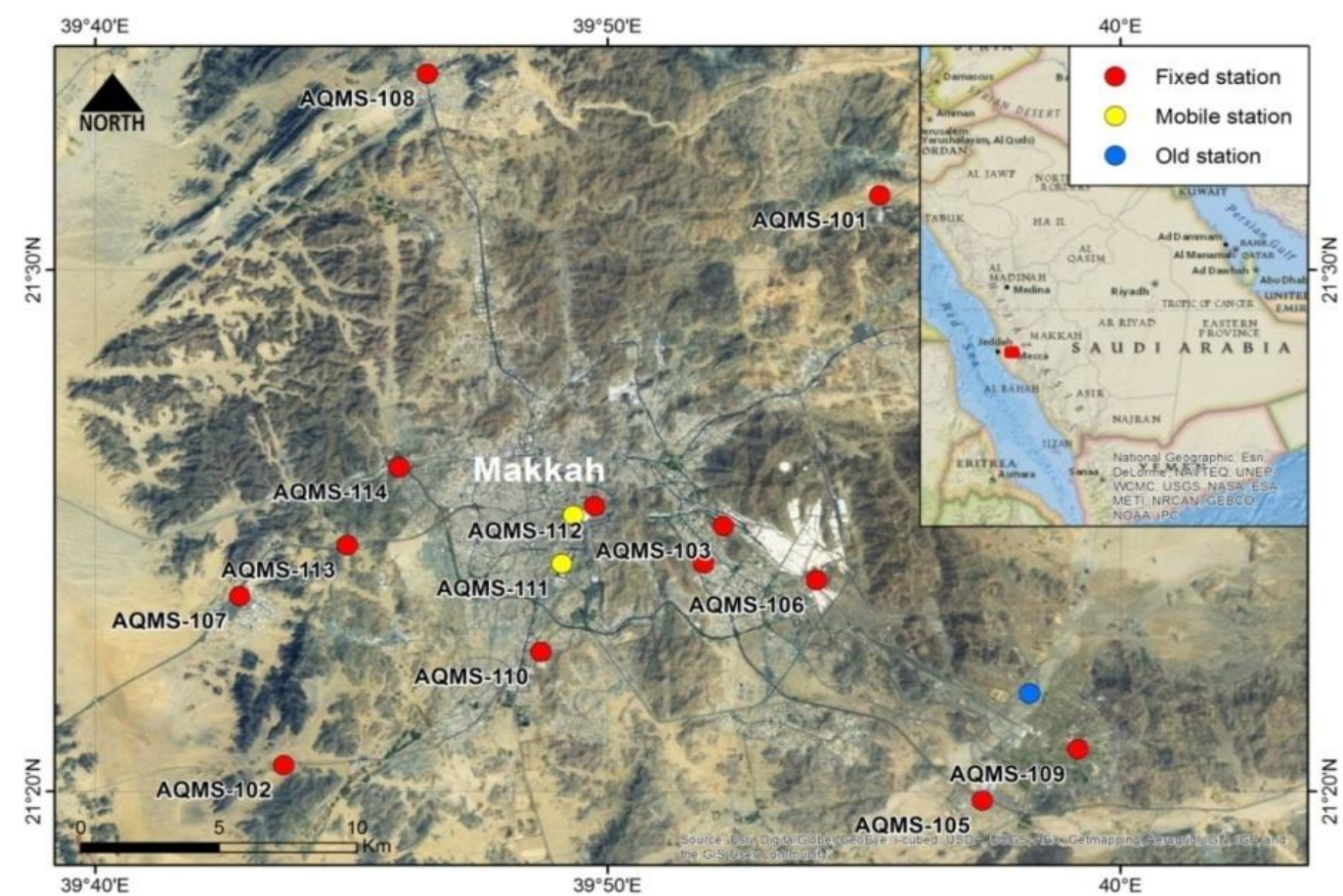

Fig. 1. Map of the air quality and meteorological monitoring sites in Makkah, Saudi Arabia, where AQMS 112 represents the PME site, where the data used in this paper were collected.

\section{RESULTS AND DISCUSSIONS}

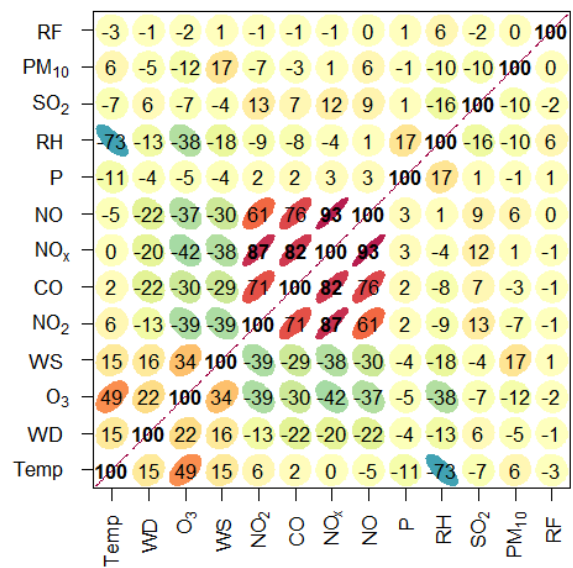

Fig. 2. Correlation plot between various air pollutants and meteorological parameters, 2012, Makkah, Saudi Arabia.

In Fig. 2, a correlation plot depicts correlation analysis of various air pollutants and meteorological parameters. In Fig. 2 the correlation plot shows the correlation between different parameters in three ways: by shape (ellipses), colour and the numeric value. The ellipses can be thought of as visual representations of scatter plot. With a perfect positive correlation a line at 45 degrees positive slope is drawn. For zero correlation the shape becomes a circle. Numeric values show the strength of the correlation, whereas the sign shows whether the correlation is negative or positive. The strongest positive correlation was found in NOx species with each other and with CO. This is expected probably due to their common emission sources, most probably road traffic and some other combustion sources. In contrast $\mathrm{SO}_{2}$ and $\mathrm{PM}_{10}$ showed weak association with $\mathrm{NOx}$ species and $\mathrm{CO}$, probably showing different sources of emission. As reported by Habeebullah [1] in Makkah most of the $\mathrm{PM}_{10}$ comes from windblown dust and sand, construction work, and resuspension of particles, rather than road traffic and therefore do not correlate well with $\mathrm{NOx}$ and $\mathrm{CO}$ which are mainly emitted by road traffic. Likewise, the mains source of $\mathrm{SO}_{2}$ in Saudi Arabia is burning of crude oils and emissions from diesels vehicles; whereas the bulk of $\mathrm{CO}$ and NOx are emitted by light vehicles, such as taxis and cars [7]. Most probably this is the reason why $\mathrm{SO}_{2}$ does not correlate well with these air pollutants. $\mathrm{O}_{3}$ is a secondary air pollutant, which is not emitted directly and rather is formed in the atmosphere by the photochemical reaction of NOx with hydrocarbons in the presence of sunlight. $\mathrm{O}_{3}$ is negatively correlated with the rest of air pollutants.

Temperature has strongest positive association with $\mathrm{O}_{3}$ $(r=0.49)$ and insignificant correlation with NOx (Fig. 2). Wind speed (WS) show positive association with $\mathrm{O}_{3}(r=0.34)$ and $\mathrm{PM}_{10}(r=0.17)$ and negative association with other air pollutants, such as NOx ( $r=-0.38)$ and CO ( $r=-0.29)$. Atmospheric pressure $(\mathrm{P})$ had weak correlation with most of the air pollutants; however the association was negative for $\mathrm{O}_{3}$ and $\mathrm{PM}_{10}$ and positive for the rest of the air pollutants. Relative humidity (RH) was negatively correlated with most of the air pollutants and the strongest negative correlation was found with $\mathrm{O}_{3}(r=-0.38)$. The mechanism and reason of the negative correlation between relative humidity and $\mathrm{O}_{3}$ are not clear. The negative correlation might be causal or not. At first glance the correlation does not seem causal and it seems like temperature is the actual cause which is affecting relative humidity and $\mathrm{O}_{3}$ concentration at the same time. Temperature is negatively affecting relative humidity and positively $\mathrm{O}_{3}$ concentration and both of these variables seem closely related. Grontoft et al., [17] concluded from his laboratory experiment that at low air humidity the equilibrium surface deposition velocity of $\mathrm{O}_{3}$ was found to decrease as more adsorbed water prevented direct contact of $\mathrm{O}_{3}$ molecules with the surface. At high air humidity the equilibrium surface deposition velocity was found to increase as the mass of water on the surface increased. Rainfall (RF) is weakly 
correlated with various air pollutants as shown in Fig. 2, correlation coefficient ranging from 0 to -2 for $\mathrm{O}_{3}$ and $\mathrm{PM}_{10}$, respectively. This might be confusing as rainfall can play a vital role in washing out atmospheric dust. However, Makkah is an arid region and receives extremely low rainfall throughout the year; this is probably why the rainfall effect is shown very weak. The effect of rainfall on various pollutants is further analysed in Fig. 4.

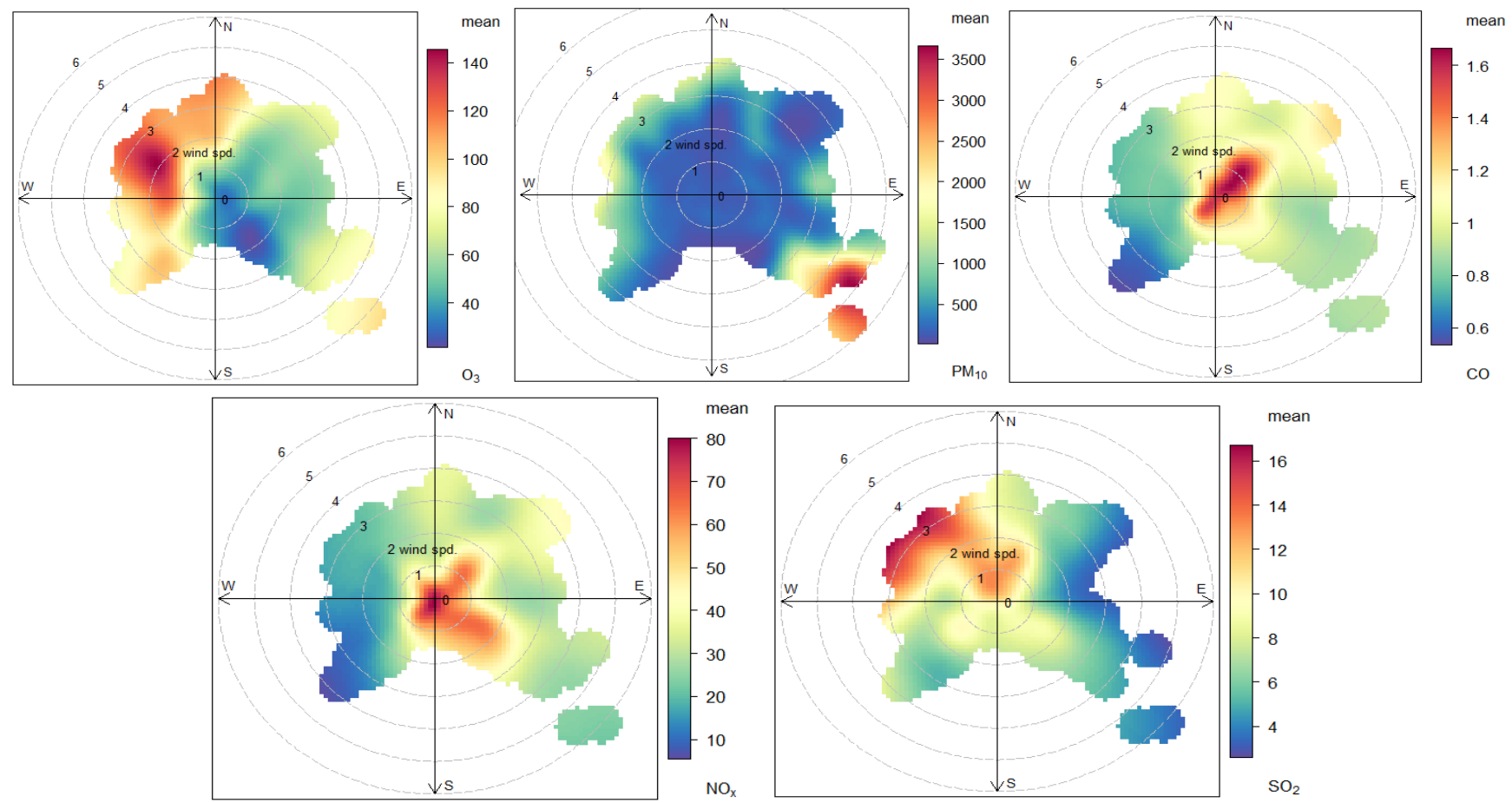

Fig. 3. Polar plots showing the effect of wind speed and wind direction on $\mathrm{PM}_{10}, \mathrm{CO}, \mathrm{NOx}, \mathrm{SO}_{2}$, and $\mathrm{O}_{3}$ during 2012 in Makkah, Saudi Arabia.
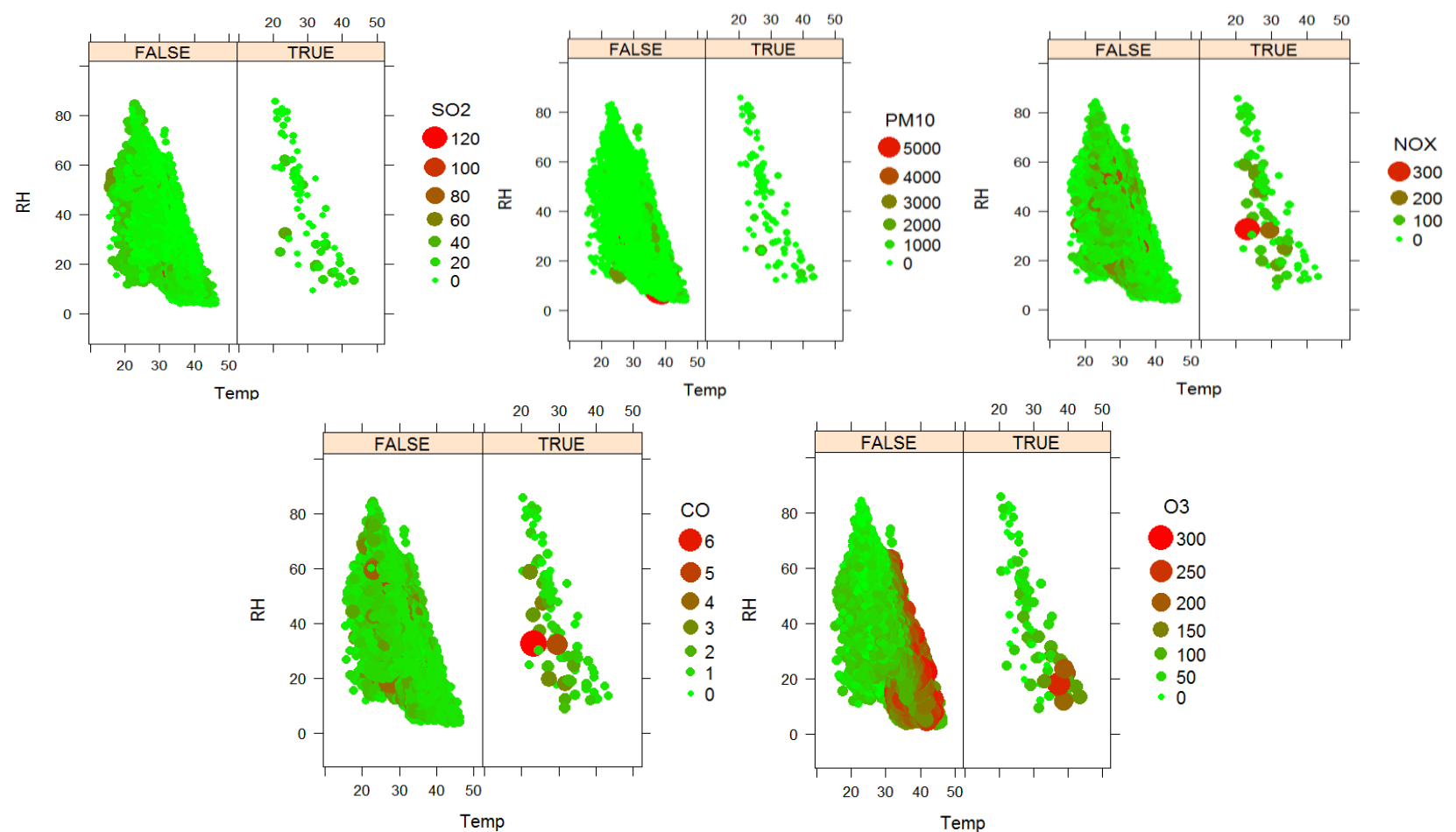

Fig. 4. The effect of temperature and wind speed are shown on $\mathrm{PM}_{10}, \mathrm{CO}, \mathrm{NOx}, \mathrm{SO}_{2}$ and $\mathrm{O}_{3}$ conditioned by rainfall, where true shows presence of rainfall (RF $>0)$ and false shows absence of rainfall $(\mathrm{RF}=0), 2012$ data from Makkah, Saudi Arabia.

Polarplots (Fig. 3) are used to investigate emission sources of air pollutants as well as the dependence of pollutants on wind speed and wind direction [15]. The plots are constructed by averaging pollutant concentration by wind speed categories $(0-1 \mathrm{~m} / \mathrm{s}, 1-2 \mathrm{~m} / \mathrm{s}$, etc.) as well as wind direction $(0-10,10-20$, etc.). The relationship of different air pollutants with wind speed and wind direction is depicted in Fig. 3 with the help of a bivariate polar plot. In polar plots the levels of different variables are shown as a continuous surface, which are calculated through using Generalized Additive Models smoothing techniques [15].

Fig. 3 (top-left) shows that highest $\mathrm{PM}_{10}$ levels are observed when wind is blowing from east or southeast at a speed of $3-6 \mathrm{~m} / \mathrm{s}$. Furthermore, wind blowing from north or northwest at about $3 \mathrm{~m} / \mathrm{s}$ shows relatively higher levels of $\mathrm{PM}_{10}$. $\mathrm{PM}_{10}$ concentrations are lower at a wind speed of $<2$ 
$\mathrm{m} / \mathrm{s}$ from all direction. It shows that as wind speed in Makkah increases it enhances re-suspension of dust particles and raises sand and dust particles from the surrounding areas, which increases the load of atmospheric suspended particulate matter, including $\mathrm{PM}_{10}$. In contrast to $\mathrm{PM}_{10}, \mathrm{NOx}$ and $\mathrm{CO}$ exhibit highest concentration at lower wind speed (wind speed $<2 \mathrm{~m} / \mathrm{s}$ ), probably high wind speed disperse locally emitted air pollutants. $\mathrm{SO}_{2}$ shows different pattern and highest concentration is linked with northwest direction. Fig. 3 clearly shows different pattern in $\mathrm{CO}, \mathrm{NOx}$ and $\mathrm{SO}_{2}$ levels from different direction. Furthermore, as mentioned above, $\mathrm{O}_{3}$ and NOx are negatively correlated as NOx (specifically $\mathrm{NO}$ ) is a scavenger of $\mathrm{O}_{3}$ and therefore $\mathrm{O}_{3}$ shows opposite pattern to that of $\mathrm{NOx} . \mathrm{O}_{3}$ levels are lower at low wind speed and show highest concentration when wind is blowing from west or northwest direction, which is an opposite trend to that of NOx.

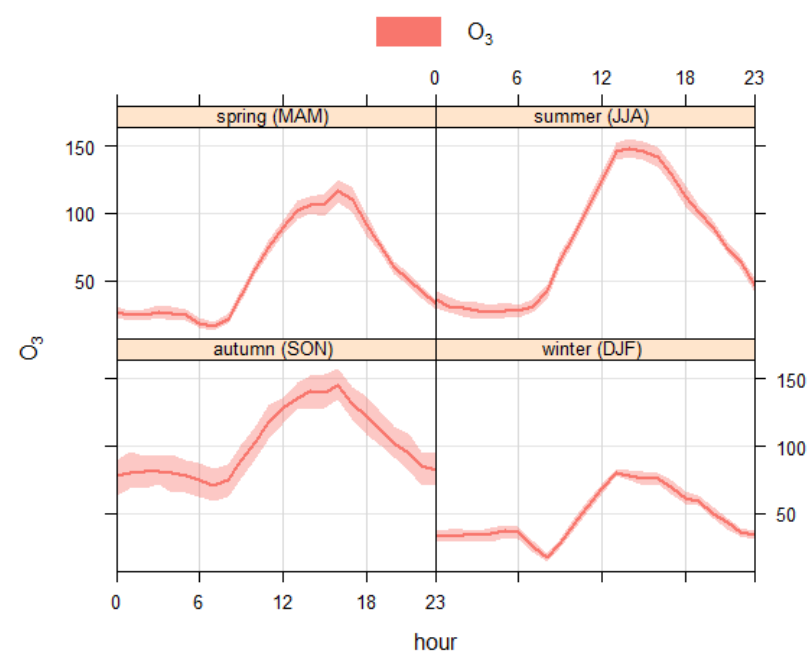

Fig. 5. Diurnal plot of O3 $(\mu \mathrm{g} / \mathrm{m} 3)$ during different seasons, where spring (MAM) represents March, April, May; summer (JJA) represents June, July, August; autumn (SON) represents September, October, December; and winter (DJF) represents December, January and February. The data are for 2012 collected in Makkah near the Holy Mosque.

Fig. 4 is an advanced scatter plot called 'loa plot', it enable us to plot $\mathrm{x}$ (here $\mathrm{RH}$ ) and $\mathrm{y}$ (Temp) and links Z (here rainfall) to plot point size and color to generate a bubbleplot style output. In Fig. 4, the effect of temperature and relative humidity on $\mathrm{PM}_{10}, \mathrm{CO}, \mathrm{NOx}, \mathrm{SO}_{2}$ and $\mathrm{O}_{3}$ are depicted. The effect is conditioned on rainfall (RF), where the condition is $\mathrm{RF}>0$. 'True' shows hours which received rainfall and 'false' corresponds to hours with no rainfall. The larger and red bubbles shows higher air pollutant concentration. In Fig. 4 (top-left) higher $\mathrm{PM}_{10}$ levels are observed on days which received no rain, which is expected as rainfall washout the atmospheric dust. Furthermore, higher levels of $\mathrm{PM}_{10}$ can be linked with high temperature and low relative humidity. The gaseous pollutant, especially $\mathrm{O}_{3}$ being a secondary air pollutant clearly shows higher levels at low relative humidity and high temperature. $\mathrm{O}_{3}$ is negative correlated with relative humidity and positively correlated with temperature (as explained above). The diurnal cycles of $\mathrm{O}_{3}$ in different seasons are shown in Fig. 5, where $\mathrm{O}_{3}$ levels are higher in summer and lower in winter season. This is probably due to the levels of temperature and relative humidity. Temperature levels are higher in summer seasons, whereas relative humidity levels are higher in winter seasons. This shows the dependence of relative humidity on temperature i.e. as temperature rises in the summer, it increases saturation point of the air which causes the relative humidity to decline. Further advanced modelling investigations are required to analyse the effect of meteorological parameters on various air pollutants in arid regions like Makkah, which is part of the ongoing research project.

\section{CONCLUSION}

In this paper the interaction between various air pollutants and meteorological parameters are analysed. It is concluded that levels of observed air pollutants not only depend on the amount of pollutants emitted from various sources but also on meteorological parameters. Meteorological parameters play important role, in secondary pollutants formation, horizontal and vertical movement, dispersion and removal from the atmospheric. Wind speed on one side disperses locally emitted air pollutants, on the other hand it encourages resuspension of dust particles and causes wind storm. Temperature, rainfall and relative humidity also play a significant role in controlling different air pollutants levels and hence it is vital to characterise their role in managing local air quality suing advance modelling approaches.

\section{ACKNOWLEDGMENT}

We are thankful to the Hajj Research Institute, Umm Al-Qura University Makkah, Saudi Arabia for sponsoring this study and for their continuous support for improving air quality conditions in the Holy Cities of Makkah and Madinah.

\section{REFERENCES}

[1] T. M. Habeebullah, "An analysis of air pollution in Makkah - A view point of source identification," Environment Asia, vol. 6, no. 2, pp. $11-17,2013$

[2] M. M. Nasralla, "Air-pollution in the semitropical Saudi urban area," Environment International, vol. 9, no. 2, pp. 55-64, 1983.

[3] N. Othman, M. Z. Mat-Jafri, and L. H. San, "Estimating particulate matter concentration over arid region using satellite remote sensing: A case study in Makkah, Saudi Arabia," Modern Applied Science, vol. 4, pp. 11-19, 2011.

[4] A. R. Seroji, "Particulates in the atmosphere of Makkah and Mina Valley during the Ramadan and Hajj seasons of 2004 and 2005," In Air Pollution XIX (Eds: Brebbia CA, Longhurst JWS, Popov V), Wessex Institute of Technology, UK, pp. 319-327, 2011.

[5] M. Khodeir, M. Shamy, M. Alghamdi et al., "Source apportionment and elemental composition of PM2.5 and PM10 in Jeddah City, Saudi Arabia," Atmospheric Pollution Research, vol. 3, pp. 331-40, 2012.

[6] S. Munir, T. M. Habeebullah, A. R. Seroji, S. S. Gabr, A. M. F. Mohammed, E. A. Morsy, "Quantifying temporal trends of atmospheric pollutants in Makkah," Atmospheric Environment, vol. 77, pp. 647-655, 2013.

[7] Presidency of Meteorology and Enviornment(PME). (2012). The royal Kingdom of Saudi Arabia 2012. [Online]. Available: http://www.pme.gov.sa/en/en_airpollution.asp

[8] C. Andersson, J. Langner, and R. Bergstrom, "Interannual variation and trends in air pollution over Europe due to climate variability during 1958-2001simulated with a regional CTM coupled to the ERA40 reanalysis," Tellus, vol. 59, pp. 77-98, 2006.

[9] D. Baur, M. Saisana, and N. Schulze, "Modelling the effects of meteorological variables on ozone concentration-a quantile regression approach," Atmospheric Environment, vol. 38, no. 28, pp. 4689-4699, 2004.

[10] C. Duenas, M. C. Fernandez, S. Canete, J. Carretero, and E. Liger, "Assessment of ozone variations and meteorological effects in an urban area in the Mediterranean Coast," The Science of The Total Environment, vol. 299, no. 1, pp. 97-113, 2002. 
[11] M. W. Gardner and S. R. Dorling, "Statistical surface ozone models: an improved methodology to account for non-linear behavior," Atmospheric Environment, vol. 34, pp. 21-34, 1999.

[12] I. A. Hassan, J. M. Basahi, I. Ismail, and T. M. Habeebullah, "Spatial distribution and temporal variation in ambient ozone and its associated NOx in the atmosphere of Jeddah City, Saudi Arabia," Aerosol and Air Quality, vol. 13, pp. 1712-1722, 2013.

[13] Air Quality Experts Group (AQEG), Ozone in the UK, The Fifth Report Produced by Air Quality Expert Group, Department for the Environment, Food and Rural Affairs, DEFRA publication London, 2009.

[14] R Development Core Team. (2012). R: A language and environment for statistical computing. $R$ Foundation for Statistical Computing. Vienna, Austria. [Online]. Available: http://www.R-project.org/

[15] D. Carslaw and K. Ropkins, "Openair - An R package for air quality data analysis," Environmental Modelling\& Software, vol. 27, no. 28 pp. 52-61, 2012.

[16] K. Ropkins. Loa package for R. [Online]. Available: http://127.0.0.1:11088/library/loa/html/loa-package.html

[17] T. Grontoft, J. F. Henriksen, and H. M. Seip, "The humidity dependence of ozone deposition onto a variety of building surfaces," Atmospheric Environment, vol. 38, pp. 59-68, 2003.

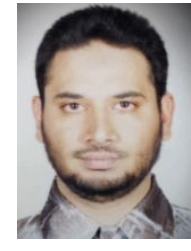

Turki M. Habeebullah was born in Makkah, Saudi Arabia on January 31, 1976. He got the Ph.D. degree in air pollution meteorology in 2010 from University of East Anglia, Norwich, United Kingdom.

$\mathrm{He}$ focuses his research on meteorology, biometeorology, microclimate, hydrology, air pollution and its impact on health, environmental sampling \& analysis, heavy metals and organic compounds, emission inventories, dispersion of air pollution and risk assessment. He is the head of Department of Environment and Health Research and works as an associate professor at the Custodian of the Two Holy Mosques Institute for Hajj and Umrah Research, Umm Al-Qura University, Makkah, Kingdom of Saudi Arabia.

Dr. Habeebullah has successfully completed several projects regarding air pollution and its impact on health and published the findings in several international journals and conference proceedings. Dr. Habeebullah has been awarded with the Employee of the Year Award in 1999, and Excellence Award in 2004 by The Custodian of the Two Holy Mosques Institute of Hajj Research, Umm Al Qura University. 